\title{
ORÇ ile Düşük Sıcaklıklı Isı Kaynaklarından Elektrik Üretilmesinde Islak ve Yeni Nesil Akışkanların Çevresel ve Termodinamik Performanslarının Karşılaştırılması
}

\section{Sadık ATA 1 (iD) Muhammed Emin BOYACIOĞLU 2 (iD Remzi ŞAHIN 1 (iD Ali KAHRAMAN 3}

${ }^{1}$ KTO Karatay Üniversitesi, Mühendislik Fakültesi, Makine Mühendisliği Bölümü, 42020, Konya, Türkiye (Sorumlu Yazar/ Corresponding Author)

2 Necmettin Erbakan Üniversitesi, Fen Bilimleri Enstitüsü, Makine Mühendisliği Ana Bilim Dalı, 42090, Konya, Türkiye

3 Necmettin Erbakan Üniversitesi, Mühendislik Fakültesi, Makine Mühendisliği Bölümü, 42090, Konya, Türkiye

\begin{tabular}{|c|c|}
\hline Makale Bilgileri & ZET \\
\hline $\begin{array}{l}\text { Makale Geçmişi } \\
\text { Geliş: } 22.02 .2021 \\
\text { Kabul: } 24.05 .2021 \\
\text { Yayın: } 30.06 .2021 \\
\text { Anahtar Kelimeler: } \\
\text { Çevresel Performans, } \\
\text { Yeni Nesil Akışkanlar, } \\
\text { Düşük Sıcaklıklı Organik } \\
\text { Rankine Çevrimi (ORÇ), } \\
\text { Ekserji. }\end{array}$ & 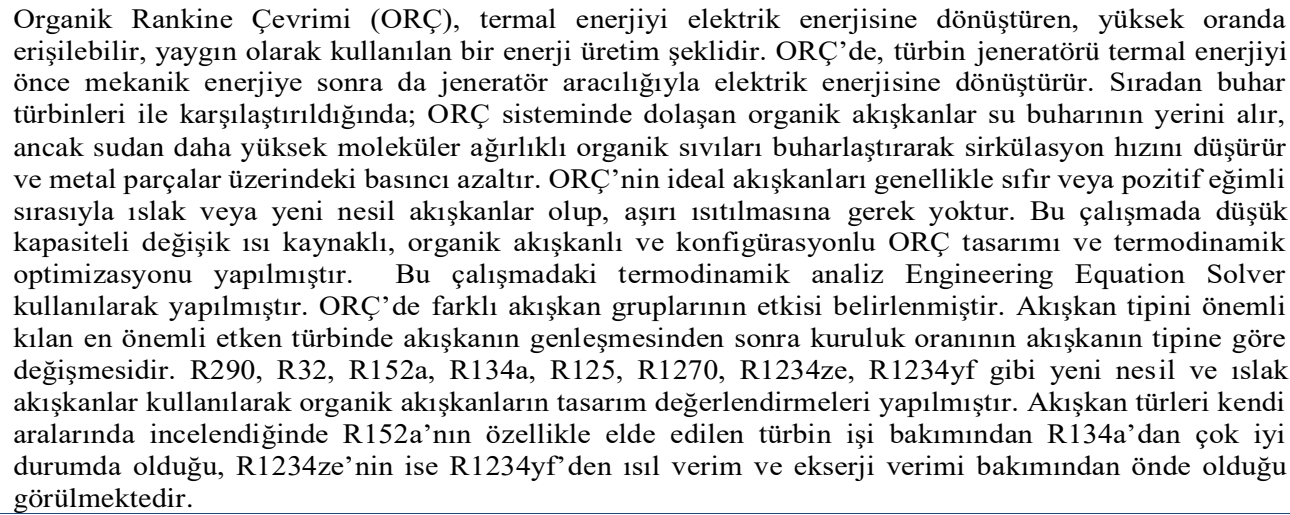 \\
\hline
\end{tabular}

\section{Comparison of Environmental and Thermodynamic Performance of Wet and New-Generation Fluids for Electricity Generation from Low Temperature Heat Sources with ORC}

Article Info ABSTRACT

Article History

Received: 22.02 .2021

Accepted: 24.05 .2021

Published: 30.06 .2021

Keywords:

Environmental

Performance, New

Generation Fluids,

Low Temperature

Organic Rankine

Cycle (ORC), Exergy.

\begin{abstract}
The organic Rankine Cycle (ORC) is a highly accessible, widely used form of energy generation that converts thermal energy into electrical energy. ORC converts the thermal energy of the turbine generator first into mechanical energy and then into electrical energy through the generator. Compared with ordinary steam turbines; Organic fluids circulating in the ORC system replace water vapor, but by evaporating organic liquids with higher molecular weight than water, it reduces the circulation rate and reduces the pressure on the metal parts. The ideal fluids of ORC are generally wet or new generation fluids with zero or positive slope, respectively, and they do not need to be overheated. In this study, ORC design and thermodynamic optimization with low capacity, different heat source, organic fluid and configuration have been made. The thermodynamic analysis in this study was performed using Engineering Equation Solver. The effect of different fluid groups has been determined in ORC. The most important factor that makes the fluid type important is that the dryness rate changes according to the type of fluid after the fluid expands in the turbine. Design evaluations of organic fluids were made using new generation and wet fluids such as R290, R32, R152a, R134a, R125, R1270, R1234ze, R1234yf. When the fluid types are examined among themselves, it is seen that R152a is in a better condition than R134a especially in terms of turbine work achieved, and R1234ze is ahead of R1234yf in terms of thermal efficiency and exergy efficiency.
\end{abstract}

Atıf/Citation: Ata, S.; Boyacıoğlu, ME.; Șahin, R.; Kahraman, A. (2021). Orç ile düșük sıcaklıklı 1S1 kaynaklarından elektrik üretilmesinde ıslak ve yeni nesil akışkanların çevresel ve termodinamik performanslarının karşılaştırılması, Necmettin Erbakan Üniversitesi Fen ve Mühendislik Bilimleri Dergisi, $3(1), 13-23$.

"This article is licensed under a Creative Commons Attribution-NonCommercial 4.0 International License (CC BY-NC 4.0)" 


\section{GİRIŞ (INTRODUCTION)}

Organik Rankine Çevrimi (ORÇ) 1sı enerjisini elektrik enerjisine çeviren, kullanılabilirliği yüksek, oldukça yaygın kullanılan bir enerji üretim biçimidir. ORÇ çalışma prensibi olarak turbo jeneratörün 1sı enerjisini önce mekanik enerjiye, sonra ise bir elektrik jeneratörü vasıtasıyla elektrik enerjisine dönüşümüdür. Normal buhar türbiniyle karşılaştırıldığında; ORC sistemi su buharı yerine moleküler ağırlığı sudan yüksek olan ve böylece daha yavaş devir hızına ve metal aksamlara daha az basınca yol açan bir organik sıvıyı buharlaştırır. ORÇ için ideal akışkanlar genellikle aşırı ısınmayı gerektirmeyen sırasıyla sıfır veya pozitif eğimli ıslak veya yeni nesil akışkanlardır.

ORÇ sayesinde yüksek verim elde edilir: \%2.5'lik bir 1sı kaybı dışında termal yağdan \%76.5 oranında termal güç 1sıya, \%21 ise elektriğe çevrilir. Bunun sonucu olarak ORÇ güvenilir, verimli bir elektrik üretme yoludur. Özellikle biyokütle ve jeotermal alanında önemli büyüme fırsatlarına ve 1sı geri kazanımı, atığın enerjiye dönüşümü ve güneş enerjisi uygulamalarındaki üstün işlevlerine sahiptir.

Literatür incelendiğinde ORÇ analizi ve akışkan seçimi hakkında yapılmış farklı çalışmaların olduğu görülür. Wang vd [1]; Hidrofloroeter kullanılarak tasarlanan ORÇ sisteminin termodinamik analizini yapmışlardır. EES planından yararlanıyorlar. HFE7000, HFE7100 ve HFE7500 organik sıvılarının birincil verimliliğgi, net gücü ve türbin boyutu faktörü türbin giriş sıcaklı̆̆g ile karşılaştırılır. Uusitalo vd. [2], ORÇ sisteminin termodinamik performansının belirlenmesinde organik akışkan türü ve akışkanın termofiziksel özelliklerinin etkisini araştırmıştır. Akışkanın kritik sıcaklığının ve molar kütlesinin sistem üzerindeki etkisi belirlenmiştir. Çalışma sonunda, buhar basıncı akışkanın kritik basıncından daha düşük olduğunda kritik sıcaklığı yüksek bir akışkan içinde yüksek verim elde edilebileceği belirtildi. Ancak, yüksek kritik sıcaklığın türbinde yüksek bir genleşme oranına yol açtığı gözlemlenmiştir. Florokarbonların ve düşük sıcaklık kritik hidrokarbonların düşük sıcaklıktaki ORÇ uygulamalarında; siloksanlar ve yüksek kritik sıcaklıklara sahip hidrokarbonların yüksek sıcaklık ORÇ uygulamaları için uygun olduğu bulunmuştur. Ergün [3] doktora çalışmasında, Çanakkale Ayvacık ilçesine bağlı Tuzla köyündeki jeotermal ORÇ santralinin termodinamik analizini yapmıştır. Analiz sonucunda, sistemdeki en yüksek kayıp değerinin kondenserde $24410 \mathrm{~kW}$ ile tespit edilmiştir. Eyidoğan [4] doktora araştırmasında biyokütleden elde edilen termal yağ1 elektrik ve 1sı (sıcak su) üretmek için kullanan ORÇ cihazının enerji ve ekserji analizini yapmıştır. Araştırmanın temelini oluşturan veriler, entegre ahşap sektöründe faaliyet gösteren bir sanayi firmasının ORÇ departmanından gelmektedir. ORÇ cihazının ana ekipmanı olan evaporatör, kondenser, türbin ve rejeneratörün enerji ve ekserji analizleri altı farklı çalışma koşulunda (tam yük ve kısmi yük) analiz edilmiştir. Giuffrida [5], yeni nesil organik sıvılar kullanan ORÇ'de $2 \mathrm{~kW}$ spiral kompresör kullanarak sistemin performansını çevresel faktörler nedeniyle analiz etti. Sonuçları şu anda kullanımda olan R245fa sıvıs1 ile karşılaştırdı. İnceleme sıvıs1; R1234yf, R1234ze(E), R1234ze(Z), R1243zf, R1336mzz(Z), R1224yd(Z), R1233zd(E). REFPROP yazılımı akışkan özellikleri için kullanılır. R245fa sıvısının GWP değeri 858 olmasına rağmen, seçilen tüm sıvılarda değerin 1'den küçük olduğu belirtilmektedir. Çalışmada 1sıl verimlilik açısından R1224yd(Z) ve R1233zd(E) sıvılarının R245fa sıvısı kullanan sistemlere göre daha iyi sonuçlar verdiği görülmüştür. Yang vd. [6], ORÇ sistemi analizinde iki sıvıyı karşılaştırarak deneysel bir çalışma yürütmüştür. Sistem, mevcut sistemde kullanılan R245fa sıvısı yerine iyi çevresel özelliklere sahip R1233zd(E) sıvısını kullanmaktadır. Deneysel çalışmada, R1233zd(E) sıvisı kullanan sistemin 1 sıl veriminin $\% 3.8$, elektrik gücünün ise $\% 4.5$ arttığ 1 tespit edilmiştir. Elde edilen verilere göre, R1233zd(E) sıvısının R245fa sıvısının yerine geçen bir sıvı olduğu söylenebilir. Behzadi vd. [7] Tahran ORÇ entegre enerji santralinin çok amaçlı optimizasyonu ve ekserji ekonomik analizi gerçekleştirildi. MATLAB tabanlı GA tabanlı çok amaçlı optimizasyon teknolojisini kullanırlar. Bademlioğlu ve ark. [8], $\Delta \mathrm{T}_{\mathrm{PP}, \mathrm{e}}$ 'nin ORÇ'nin ekserji performansı üzerindeki etkisini araştırmıştır. TPe'yi 5$20{ }^{\circ} \mathrm{C}$ arasında değiştirmenin farklı organik akışkanlarla hazırlanmış sistemler üzerindeki etkisini 
belirlenmiştir. Şahin vd. [9], ORÇ performansında akışkan seçiminin rolü ekserji analizi yapılarak belirlenmiştir. Çalı̧̧ma sonucunda, en yüksek 1sıl verim \%7.78 ve ekserji verimine \%41.05 R290 akışkanının ulaştığı görülmüştür. R290 akışkanında oluşan tersinmezliğin \%60'ının evaporatörde olduğu, \%30'unun da kondenserde olduğunu belirlemişlerdir. Xi vd. [10], R123, R11, R245ca, R245fa, R113 ve R141b olmak üzere altı farklı organik akışkanın performansı karşılaştırılmıştır. R245fa'nın net güç maksimizasyonu için en iyi değere ulaştığ görülmüştür. R141b ve R11 akışkanlarının daha iyi termodinamik performans verdiklerini tespit etmişlerdir. Rahbar vd. [11], ORÇ'de küçük ölçekli radyal türbinin performans1 8 organik akışkan kullanılarak incelenmiştir. Çalışma sonucunda, radyal türbin veriminin \%82.9 ile \%84 arasında olduğu belirtilmiştir. Sarkar [12], ORÇ'de maksimum 1sı geri kazanımı için $\Delta \mathrm{T}_{\mathrm{PP}, \mathrm{e}}$ tasarımı ve optimizasyonu üzerinde çalışmıştır. Optimum noktalarda düşük kütlesel debi gereksinimi, yüksek ekserji gerimi, düşük türbin boyutu bakımından amonyak akışkanında; yüksek güç çıktısı ve 1sı geri kazanımı verimi bakımından ise izopentan akışkanında en iyi sonuçlara ulaşılmışıtır. Li vd. [13], çevresel özellikleri iyi durumda yeni nesil organik bir akışkan olan R1234ze ile tasarladıkları kritik altı ORÇ ve transkritik ORÇ sisteminin performans analizini yapmışlardır. Isı kaynağı giriş sıcaklığı $100-160{ }^{\circ} \mathrm{C}$ olan sistemler için kritik altı ORÇ’nin; $160-200{ }^{\circ} \mathrm{C}$ olan sistemler için ise transkritik ORÇ’nin uygun olduğu tespit edilmiştir. Zhu vd. [14], ORÇ performansında organik akışkanların önemini incelediler. Çalışma sonunda, daha yüksek bir net güç değeri elde etmek için organik akışkanların kritik sıcaklığı ile 1sı kaynağının sıcaklığı arasındaki farkın küçük olması gerektiğini belirlediler. Velez vd. [15], ORÇ sisteminin analizi için su, bazı hidrokarbonlar ve soğutucular gibi farklı akışkanlar üzerinde çalışmışlardır. Çalışmalarında, basınç oranı ve türbin giriş sıcaklığının artışı ile sistem 1sıl veriminin arttığını belirtmişlerdir. Maksimum 1 sıl verim değeri ise $\% 9$ olarak belirlemişlerdir. Javanshir ve Sarunac [16], Islak, izantropik ve kuru akışkan gruplarından olmak üzere 23 farklı akışkan ile çalışan ORÇ’nin performansı 1 sıl verim ve net güç çıktısı bakımından analiz edilmiştir. Çalışma sonucunda izantropik akışkanların veriminin kuru ve 1slak akışkanlara göre daha iyi olduğu sonucuna varılmıştır.

$\mathrm{Bu}$ çalışmanın amacı ORÇ sisteminde sslak ve yeni nesil akışkanların sistem parametreleri üzerindeki etkilerini belirlemek, akışkanların sistem üzerindeki çevresel ve termodinamik etkilerini karşılaştırmaktır. Çalı̧̧mada 8 farklı akışkan kullanılmış olup belirlenen sistem parametreleri için en iyi performans gösteren farklı sınıflardan akışkanlar belirlenmiştir.

\section{MATERYAL VE METOT (MATERIALS AND METHODS)}

Bu çalışmada ıslak ve yeni nesil organik akışkanlar kullanılarak tasarlanan ORÇ'nin termodinamik analizi ve özellikleri Engineering Equation Solver (EES) belirlenmiştir. EES yazılımını kullanma nedenleri; veri tabanında bulunan birçok organik sıvının termofiziksel özelliklerini içermesidir. Termodinamik analiz için gerekli denklemler sisteme girilerek, aynı anda birçok parametrede meydana gelen değişikliklere yanıt olarak istenen sonuçlar elde edilebilir. Farklı sıvılar kullanmanın sistem performansı üzerindeki etkisini görmek kolaydır. EES yazılımı, geri döndürülemez ilişkiyi sistemle işleyerek, geri döndürülemez değeri belirli bir sıcaklık veya basınç aralığında negatif bir değere ulaşan bileşenleri tespit etmek için denklem çözücü işlevini ve termodinamik verilerini kullanır. Bu şekilde hazırlanan modelin termodinamiğin ikinci yasasına uygunluğu kontrol edilmiştir.

ORÇ'de üç farklı tip akışkanın sistem performansındaki etkisi belirlenmiştir. Şekil 1'de ORÇ çalışma prensibi gösterilmiştir. Organik akışkan (ara sıvı) düşük basınçtan yüksek basınca pompalanır. Akışkan sıvı halde olduğu için, pompa az miktarda enerji girişi gerektirir. Yüksek basıç̧lı sıvı, sabit bir basınçta büyük bir 1S1 kaynağı tarafından 1sıtıldığı ve doymuş kuru buhar haline geldiği kazana girer. Gerekli giriş enerjisi, bir entalpi-entropi tablosu (h-s diyagramı veya Mollier diyagramı) kullanılarak grafiksel olarak kolayca hesaplanabilir veya gerekli giriş enerjisi, bir buhar ölçer kullanılarak dijital olarak kolayca hesaplanabilir. Doymuş kuru buhar fazındaki çalışma sıvısı, enerji üreten bir türbin tarafından genişletilir. Bu, sıvı ve buhar 
basıncını düşürür ve biraz yoğunlaşmaya neden olabilir. Islak buhar, yoğunlaştırıcıya (yoğunlaştırıcı) girer ve sabit bir basınçta doymuş bir sıvıya yoğunlaşır. Sonuç olarak termal enerji mekanik enerjiye dönüştürülerek elektrik enerjisi elde edilmiş olur.

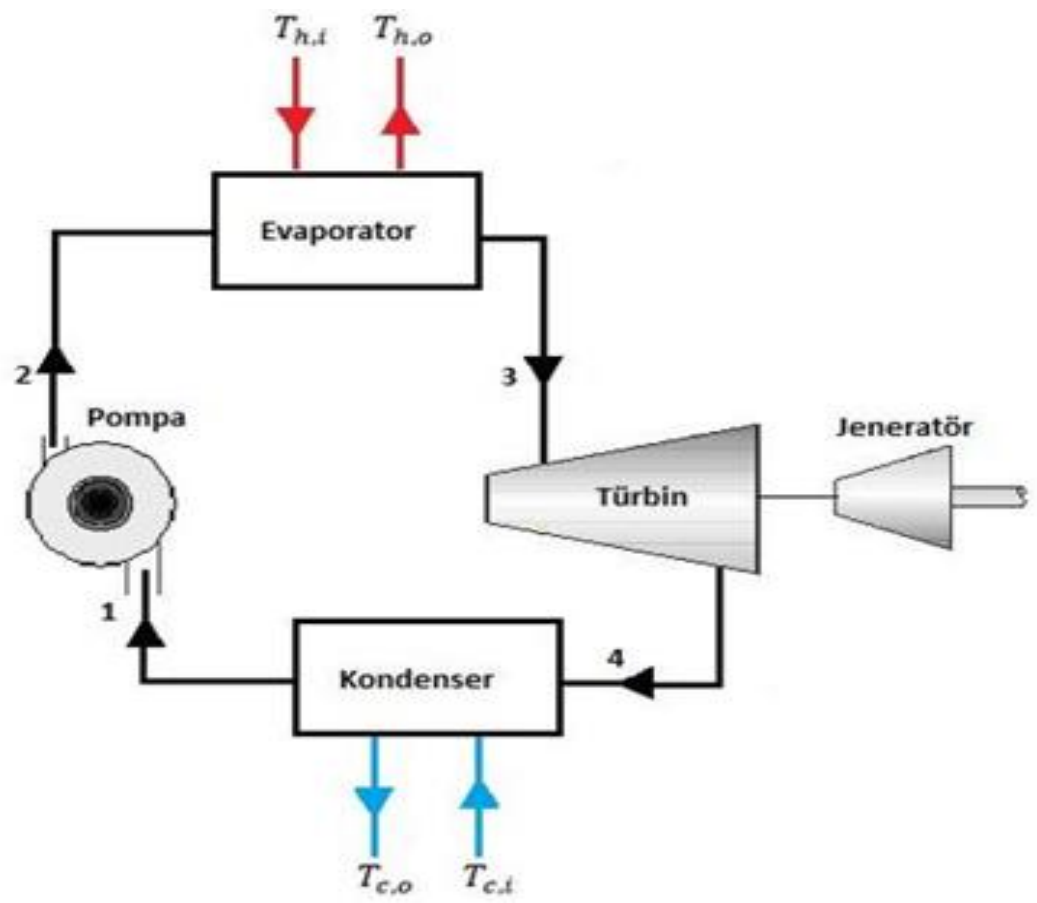

Şekil 1. Organik Rankine Çevrimi Çalışma Prensibi

$\mathrm{Bu}$ çalışmada ORÇ'de farklı akışkan gruplarının etkisi belirlenmiştir. Akışkanlar doymuş buhar eğrisinin eğimine göre Şekil 2 'de gösterildiği gibi kuru, yeni nesil ve sslak olmak üzere üç grupta incelenir. Akışkan tipini önemli kılan en önemli etken türbinde akışkanın genleşmesinden sonra kuruluk oranının akışkanın tipine göre değişmesidir. Akışkanların T-s diyagramlarındaki doyma eğrilerinin eğimi pozitif olduğunda akışkan kuru, negatif olduğunda sslak ve sonsuz olduğunda ise izantropik olarak isimlendirilir.

Organik akışkanlar 1slak ve yeni nesil olmak üzere iki farklı kategori altında sınıflandırılarak performansı karşılaştırılmıştır. Islak akışkanlardan 6, yeni nesil akışkanlardan 2 olmak üzere toplam 8 akışkanın performansı aynı tasarım parametreleri altında belirlenmiştir. Bu akışkanlar Tablo 1'de belirtilmiştir.

ORÇ’nin jeotermal 1sı kaynaklı uygulamaları kapsamında 1sı kaynağı sıcaklığ $110{ }^{\circ} \mathrm{C}$ olarak sabit belirlenmiştir. Soğutma suyu sıcaklığ ise $^{2} 5^{\circ} \mathrm{C}$, türbin ve pompa izantropik verimleri de \%75 olarak ele alınmıştır. Ölü nokta basıncı ve sıcaklığı sırasıyla $100 \mathrm{kPa}$ ve $25^{\circ} \mathrm{C}$ olarak kabul edilmiştir. Bu bölümde yapılan diğer kabuller aşağıda belirtilmiştir.

- Bütün prosesler kararlı şartlardadır.

- Evaporatör ve kondenserdeki basınç kayıpları ihmal edilmiştir. Boru hatlarındaki kayıplar ihmal edilmiştir.

- Analizde tüm ekipmanlar adyabatik olarak kabul edilmiş ve yüzeyleri ile çevre arasında bir 1s1 transferinin olmadığı varsayılmıştır.

- Potansiyel ve kinetik enerji değişimleri ihmal edilmiştir. 

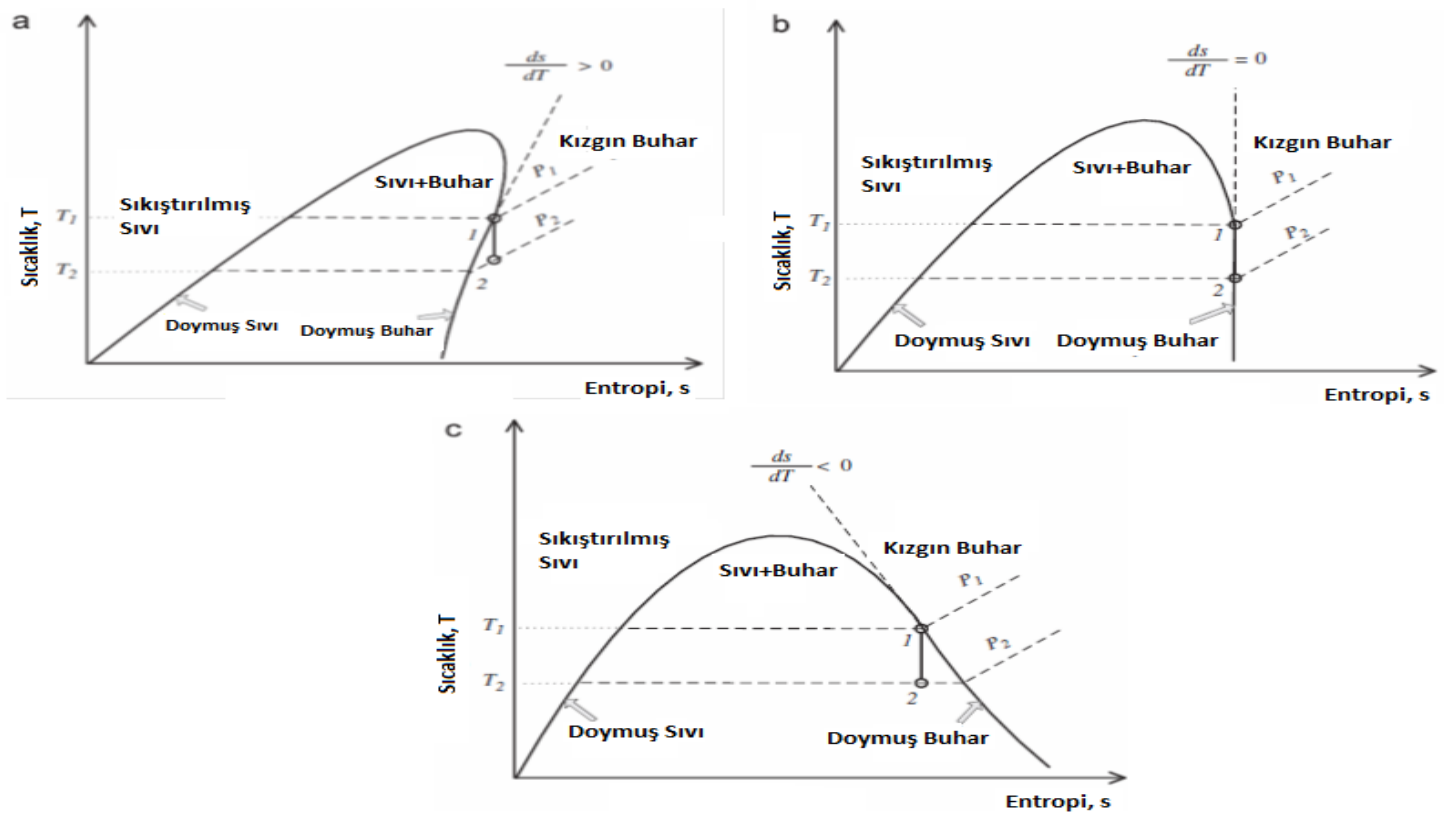

Şekil 2. Organik Akışkanların T-s Diyagramında Gösterimi a) Kuru, b) İzantropik, c) Islak [17].

Tablo 1. Farkll Kategorilerden Belirlenen Organik Aklşkanlar

\begin{tabular}{cc}
\hline Islak Akışkanlar & Yeni Nesil Akışkanlar \\
R290 & R1234ze \\
R32 & R1234yf \\
R152a & \\
R134a & \\
R125 & \\
R1270 & \\
\hline
\end{tabular}

ORÇ'nin termodinamik analizinde kullanılan denklemler aşağıda belirtilmiştir.

Aşağıdaki çizelgede verilen denklemlerde; $\eta_{\mathrm{t}}$ ve $\eta_{\mathrm{p}}$ sırasıyla türbin ve pompanın izantropik verimleri, $T_{h, i}$ ve $T_{h, o}$ sırasıyla 1sı kaynağı giriş-çıkış; $T_{c, i}$ ve $T_{c, o}$ ise sırasıyla soğutma suyu giriş-çıkış sıcaklıklarıdır. Tablo 2'de verilen $\mathrm{T}_{\mathrm{h}}$ ve $\mathrm{T}_{\mathrm{c}}$ ise denklem (1) ve (2)'de tanımlanmıştır.

$$
\begin{aligned}
& T_{h}=\left(T_{h, i}-T_{h, o}\right) / \operatorname{Ln}\left(T_{h, i}-T_{h, o}\right) \\
& T_{e}=\left(T_{c, i}-T_{c, o}\right) / \operatorname{Ln}\left(T_{c, i}-T_{c, o}\right)
\end{aligned}
$$

\section{BULGULAR (RESULTS)}

Organik Akışkanların Termofiziksel Özelliklerinin Değerlendirilmesi (Evaluation of Thermophysical Properties of Organic Fluids)

Tablo 3'de ORÇ tasarımında kullanılan ıslak ve yeni nesil akışkanların termofiziksel özellikleri karşılaştırılmıştır. Seçilen 1slak akışkanlardan kaynama noktası sıcaklığı en düşük olan akışkan R32, yeni nesil akışkanlarda ise R1234yf olarak belirlenmiştir. Kritik sıcaklık değeri 1slak akışkanlar arasından en yüksek olan akışkan R152a, yeni nesil akışkanlar arasında ise R1234ze olduğu belirtilmiştir. R125 ve R32'nin kritik sıcaklıkta daha düşük değerlere sahip olduğu, diğer akışkanların birbirine yakın olduğu görülebilmektedir. $30{ }^{\circ} \mathrm{C}$ ye karşılık gelen tüm akışkanların yoğuşma basıncını ve $100{ }^{\circ} \mathrm{C}$ 'lik buharlaşma 
basıncını kontrol ederken, sslak akışkanın diğer akışkan türlerinden daha yüksek bir basınç değerine sahip olduğuna dikkat etmek önemlidir. Islak sıvıda R152a ve R134a en düşük basınç değerine ulaşır.

Tablo 2. ORÇ Termodinamik Analiz Bağıntıları

\begin{tabular}{|c|c|c|}
\hline BİLEŞENLER & ENERJİ ANALİZI & EKSERJİ ANALİŻ \\
\hline Pompa & $\begin{array}{l}\text { Pompa İşi }(\mathrm{kJ} / \mathrm{kg}) \\
w_{p}=\left(h_{2}-h_{1}\right)=\left(h_{2 s}-h_{1}\right) / \eta_{p}\end{array}$ & $\underset{i_{p}=T_{0}\left(s_{2}-s_{1}\right)}{\operatorname{Pompa}}$ Tersingezi $(\mathrm{kJ} / \mathrm{kg})$ \\
\hline Evaporatör & $\begin{array}{l}\text { Evaporatör 1s1 girdisi }(\mathrm{kJ} / \mathrm{kg}) \\
q_{e}=\left(h_{\mathrm{a}}-h_{2}\right)\end{array}$ & $\begin{array}{l}\text { Evaporatör Tersinmezliği }(\mathrm{kJ} / \mathrm{kg}) \\
i_{e}=T_{0}\left[\left(s_{2}-s_{2}\right)-\left(h_{2}-h_{2}\right) / T_{\mathbb{h}_{\mathrm{h}}}\right]\end{array}$ \\
\hline Türbin & $\begin{array}{l}\text { Türbin İşi }(\mathrm{kJ} / \mathrm{kg}) \\
w_{t}=\left(h_{a}-h_{4}\right)=\left(h_{a}-h_{4 s}\right) \eta_{t}\end{array}$ & $\begin{array}{l}\text { Türbin Tersinmezliği }(\mathrm{kJ} / \mathrm{kg}) \\
i_{t}=T_{0}\left(s_{4}-s_{9}\right)\end{array}$ \\
\hline Kondenser & $\begin{array}{l}\text { Kondenserde Attlan Is1 Miktarı }(\mathrm{kJ} / \mathrm{kg}) \\
q_{c}=\left(h_{4}-h_{1}\right)\end{array}$ & $\begin{array}{l}\text { Kondenser Tersinmezlĭgi }(\mathrm{kJ} / \mathrm{kg}) \\
i_{k}=T_{0}\left[\left(s_{1}-s_{4}\right)+\left(h_{4}-h_{1}\right) / T_{e}\right]\end{array}$ \\
\hline \multirow{3}{*}{ Sistem } & Net İş $(\mathrm{kJ} / \mathrm{kg})$ & $\begin{array}{l}\text { Toplam Tersinmezlik }(\mathrm{kJ} / \mathrm{kg}) \\
i_{\text {Toplam }}=i_{\mathrm{p}}+i_{e}+i_{\mathrm{t}}+i_{e}\end{array}$ \\
\hline & $\begin{array}{l}w_{\text {net }}=q_{e}-q_{c} \\
\text { Is1l Verim }\end{array}$ & $\begin{array}{l}\text { Harcanan Ekserji }(\mathrm{kJ} / \mathrm{kg}) \\
\varepsilon_{\text {harcanan }}=\left[1-T_{0} / T_{H}\right] q_{e}+w_{p}\end{array}$ \\
\hline & $\eta_{\text {terl }}=w_{\text {net }} / q_{e}$ & $\begin{array}{l}\text { Ekserji Verimi } \\
\eta_{H}=1-i_{\text {Toplam }} / e_{\text {harcanan }}\end{array}$ \\
\hline
\end{tabular}

Tablo 3. Kendi kategorilerinde en iyi performans gösteren aklşkanların ve yeni-nesil organik akışkanların çevresel etkisi [18]

\begin{tabular}{|l|c|c|c|c|c|c|c|c|}
\hline Akışkanlar/ Özellikler & $\mathbf{R 2 9 0}$ & $\mathbf{R 3 2}$ & $\mathbf{R 1 2 5}$ & $\mathbf{R 1 2 7 0}$ & $\mathbf{R 1 5 2 a}$ & $\mathbf{R 1 3 4 a}$ & $\mathbf{R 1 2 3 4 y f}$ & R1234ze \\
\hline $\begin{array}{l}\text { Molekül Ağırlı̆̆ } \\
(\mathrm{g} / \text { mol })\end{array}$ & 44.10 & 52.02 & 120.02 & 42.08 & 66.05 & 102.03 & 114.04 & 114.04 \\
\hline Kaynama Noktası $\left({ }^{\circ} \mathrm{C}\right)$ & -42.1 & -51.7 & -48.1 & -47.7 & -24 & -26.1 & -29.3 & -18.8 \\
\hline $\begin{array}{l}\text { Kritik Sicaklık Değeri } \\
\left({ }^{\circ} \mathrm{C}\right)\end{array}$ & 96.7 & 78.1 & 66 & 92.4 & 113.3 & 101.1 & 94.85 & 109.52 \\
\hline $\begin{array}{l}\text { Kritik Basinç Değgeri } \\
(\text { MPa })\end{array}$ & 4.25 & 5.78 & 3.62 & 4.66 & 4.52 & 4.06 & 3.38 & 3.63 \\
\hline $\begin{array}{l}\text { ASHRAE standartları } \\
\text { güvenlik sinıf } i\end{array}$ & $\mathrm{~A} 3$ & $\mathrm{~A} 2$ & $\mathrm{~A} 1$ & $\mathrm{~A} 3$ & $\mathrm{~A} 2$ & $\mathrm{~A} 1$ & $\mathrm{~A} 2 \mathrm{~L}$ & $\mathrm{~A} 2 \mathrm{~L}$ \\
\hline ODP & 0 & 0 & 0 & 0 & 0 & 0 & 0 & 0 \\
\hline GWP & 20 & 675 & 3500 & 20 & 124 & 1430 & 4 & 6 \\
\hline
\end{tabular}

Organik Akışkanların Çevresel Özelliklerinin Değerlendirilmesi (Evaluation of Environmental Properties of Organic Fluids)

Tablo 4'de ORÇ tasarımında kullanılan kuru ve izantropik akışkanların çevresel özellikleri karşılaştırılmıştır. Ozon Yok Etme Potansiyeli (ODP) 8 akışkan için 0 olduğu ve Küresel Isınma Potansiyeli (Global Warming Potential-GWP) değerinin en yüksek R125 akışkanında olduğu görülmektedir. 
Tablo 4. Islak ve Yeni Nesil Akışkanların Çevresel Özellikleri [18]

\begin{tabular}{lcccccccc}
$\begin{array}{l}\text { Aksskanlar/ } \\
\text { Özellikler }\end{array}$ & R290 & R32 & R152a & R134a & R125 & R1270 & R1234yf & R1234ze \\
$\begin{array}{l}\text { ASHRAE standartları } \\
\text { güvenlik sınıf }\end{array}$ & A3 & A2 & A2 & A1 & A1 & A3 & A2L & A2L \\
ODP & 0 & 0 & 0 & 0 & 0 & 0 & 0 & 0 \\
GWP & 20 & 675 & 124 & 1430 & 3500 & 20 & 4 & 6 \\
\hline
\end{tabular}

Bu bölümde ORÇ tasarımında kullanılan akışkanların çevresel özellikleri kapsamında GWP ve ASHR güvenlik sınıfı belirtilmiştir. ASHR güvenlik sınıfına dair gruplandırma da Şekil 3'de verilmiştir.

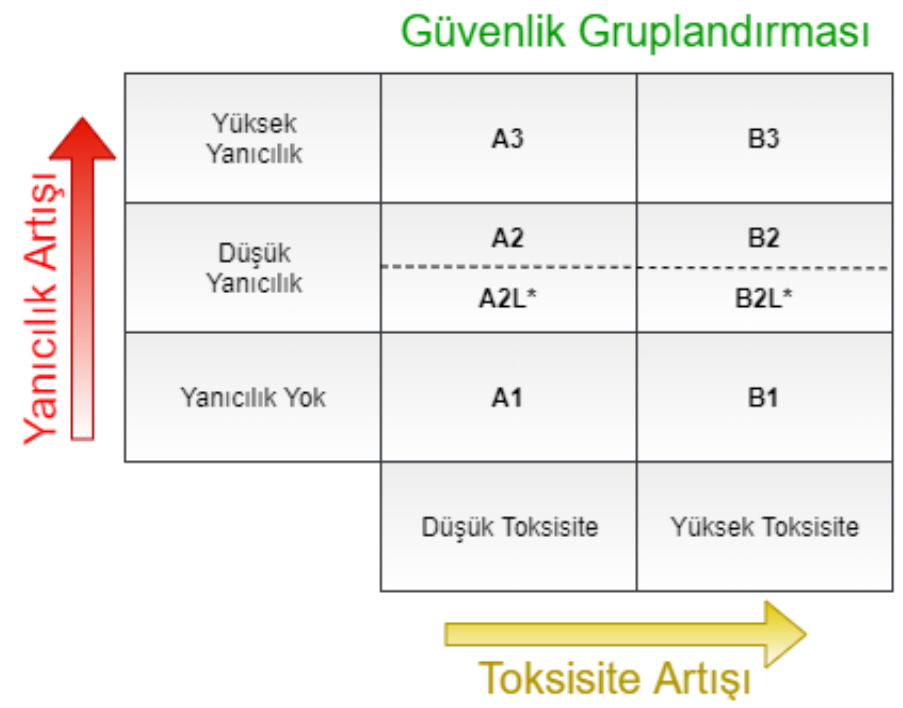

Şekil 3. Akışkanların çevresel özelliklerini belirleyen güvenlik gruplandırması

*Şekil 3'de A2L ve B2L düşük yanıcılık değeri olan ve maksimum yanma hızı $10 \mathrm{~cm} / \mathrm{s}$ olan akışkanları ifade etmektedir.

\section{Organik Akışkanların Termodinamik Performanslarının Belirlenmesi (Determination of Thermodynamic Performance of Organic Fluids}

Bu bölümde ıslak ve yeni nesil akışkanların ORÇ performansına etkisi belirlenmiş̧ir. Performans parametreleri pompa işi $(\mathrm{kJ} / \mathrm{kg})$, türbin işi $(\mathrm{kJ} / \mathrm{kg})$, $1 \mathrm{~s} 1$ girdisi $(\mathrm{kJ} / \mathrm{kg})$ 1sıl verim ve ekserji verimi olarak belirlenmiştir. Isı kaynağı sıcaklığı jeotermal uygulamaları kapsamında $110{ }^{\circ} \mathrm{C}$ olarak belirlenmiştir. Buharlaşma sıcaklığının $65-100{ }^{\circ} \mathrm{C}$ arasında değişmesinin sistem performansı üzerindeki etkisi belirlenmiştir.

Şekil 4'de görüldügüü üzere ıslak akışkanların $100^{\circ} \mathrm{C}$ buharlaşma sıcaklığı altında ulaştıkları analiz sonuçları dikkate alınarak en iyi performans gösteren 2 1slak akışkanın R152a ve R134a olduğu görülmektedir. Isıl verim ve ekserji verimi yönünden en iyi değerlere R152a'da ulaşıldığı ve aynı zamanda sadece R134a'da belli bir buharlaşma sıcaklığı değerinden sonra $\left(98{ }^{\circ} \mathrm{C}\right)$ 1sıl verim ve ekserji veriminin azalmaya başladığı gözlenmemiştir. 
En düşük performans değerlerinin R125'li sistemde elde edildiği, türbin işi performansı bakımından en iyi değerlere R290 ve R1270'li sistemde ulaşılmasına rağmen, yüksek 1s1 girdisi ihtiyacından dolayı 1sı1 verim sıralamasında R152a ve R134a'nın gerisinde kaldığı belirlenmiştir. R134a'nın yüksek 1sıl verim ve ekserji veriminin olmasının yanı sıra toplam tersinmezlik değerinin de düşük olduğu görülmektedir. Yeni nesil akışkanlarda ise 1sıl ve ekserji veriminde R1234ze akışkanın yüksek olduğu görülmektedir.

Şekil 5'te tüm akışkanların $100{ }^{\circ} \mathrm{C}$ buharlaşma sıcaklığı altında türbin giriş basıncı, buharlaşma entalpisi $\left(\mathrm{h}_{\mathrm{fg}}\right)$, türbin çıkışı buharın kuruluk derecesi gibi değerler belirlenmiştir. En yüksek Türbin giriş basınc1 1slak akışkanlarda R32'de yeni nesil akışkanda ise R1234yf'de olduğu belirlenmiştir. Islak akışkanlarda buharlaşma entalpisi değeri en fazla R290 en düşük R125 de gözlemlenirken yeni nesil akışkanlarda ise R1234ze'nin, R1234yf den fazla buharlaşma entalpisi değerine ulaştığ belirlenmiştir. İncelenen diğer bir parametrede ise türbin çıkış kuruluk derecesi en fazla R134'a de gözlemlenirken yeni nesil akışkanda ise R1234ze'de gözlemlenmiştir.

\section{TARTIŞMA VE SONUÇLAR (DISCUSSION AND CONCLUSIONS)}

$\mathrm{Bu}$ çalışmada, organik akışkan seçimi 3 farklı kriter üzerinden değerlendirilmiştir. Bunlar termofiziksel özellik, çevresel özellik ve termodinamik performanstır. Bu çalışmada EES, sslak ve yeni nesil organik akışkanlar kullanılarak tasarlanan ORÇ'nin termodinamik özelliklerini belirlemiştir. R290, R32, R152a, R134a, R125, R1270, R1234ze, R1234yf gibi yeni nesil ve ıslak akışkanlar kullanılarak organik akışkanların tasarım değerlendirmeleri yapılmıştır. Aynı zamanda 1slak akışkanlar için buharlaşma sıcaklığı değişiminin performans parametreleri üzerindeki etkisi gözlemlenmiştir.

Belirlenen akışkanların çevresel özellikleri incelendiğinde tüm akışkanlar için ODP değerlerinin 0 olduğu görülürken, GWP değerlerinde yeni nesil akışkanların ıslak akışkanlara göre daha düşük değerlere sahip oldukları belirlenmiştir. ASHRAE standartları güvenlik sınıfına göre en düşük yanıcılık ve toksisite değerlerine R134a ve R125 sahip iken bu akışkanlar aynı zamanda en yüksek GWP değerlerine de sahip oldukları görülmüştür.

$\mathrm{Bu}$ çalışma sonucunda yeni nesil organik akışkanların ıslak akışkan türüne yakın özellikler sergilediği görülmüştür. Fakat yeni nesil organik akışkanların daha düşük yoğuşma ve buharlaşma basınç değerlerine sahip olduğu ve daha az pompa gücüne ihtiyaç duyduğu dikkat çekmektedir. Performans parametreleri altında ise özellikle R1234ze'nin R134a'dan daha iyi fakat R152a'dan ise daha düşük performansa sahip olduğu görülmektedir.

Tüm akışkanların $100^{\circ} \mathrm{C}$ buharlaşma sıcaklığı altında 1sıl verim, türbin işi, ekserji verimi ve toplam tersinmezlik değerleri belirlenmiştir. Akışkanlar kendi kategorilerinde incelendiğinde R152a'nın özellikle elde edilen türbin işi bakımından $33.05 \mathrm{~kJ} / \mathrm{kg}$ ile R134a'dan $(18.03 \mathrm{~kJ} / \mathrm{kg})$ daha iyi performans gösterdiği, R1234ze'nin ise R1234yf'den 1s1l verimde sirasiyla \%9.77 ve \%8.23, ekserji veriminde sirasiyla \%52.3 ve \%45.98 olarak önde olduğu görülmektedir. 


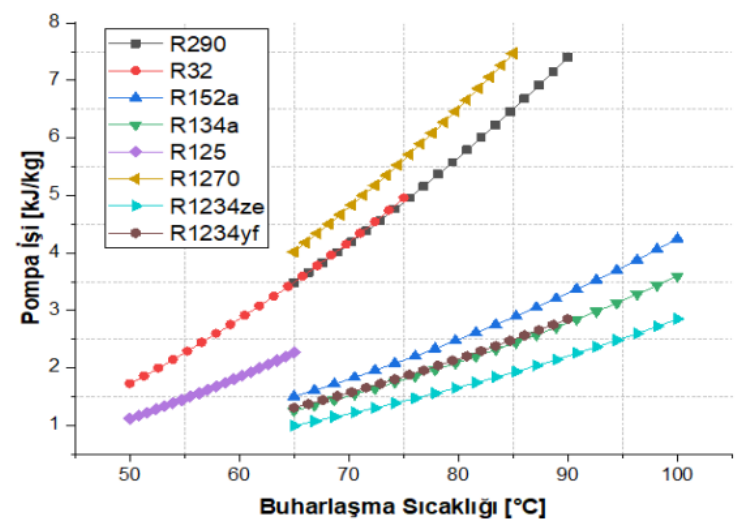

(a)

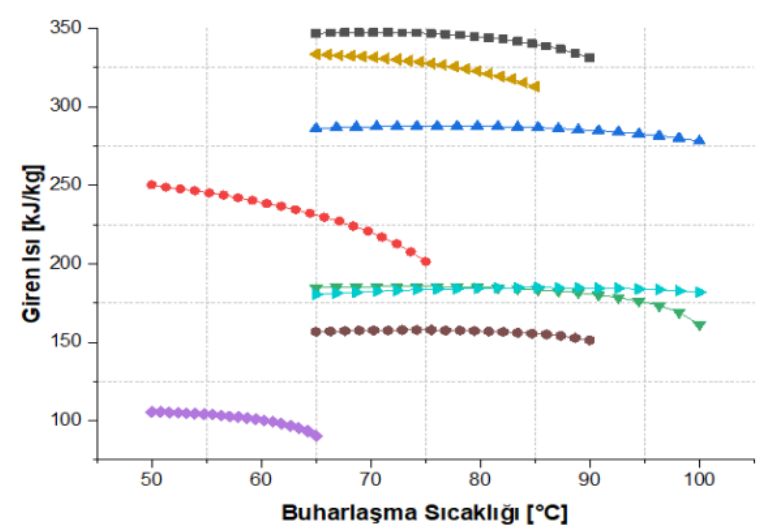

(c)

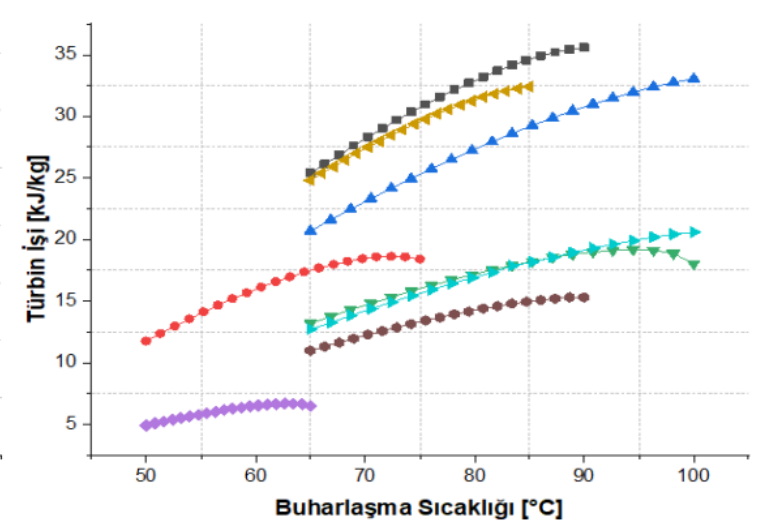

(b)

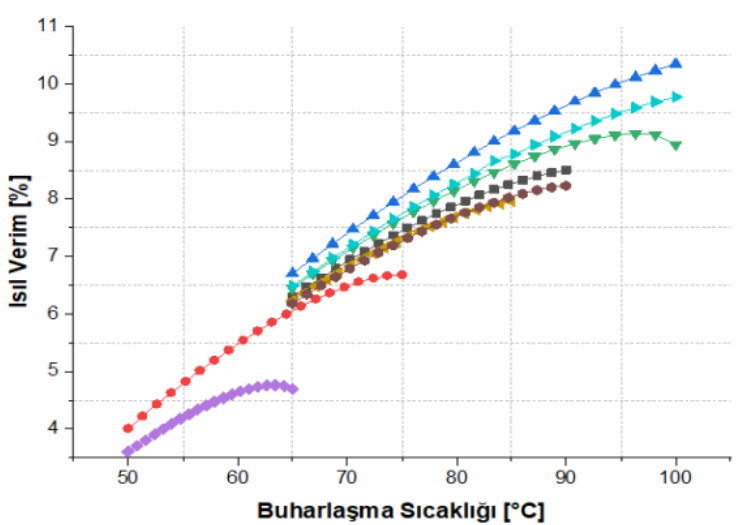

(d)

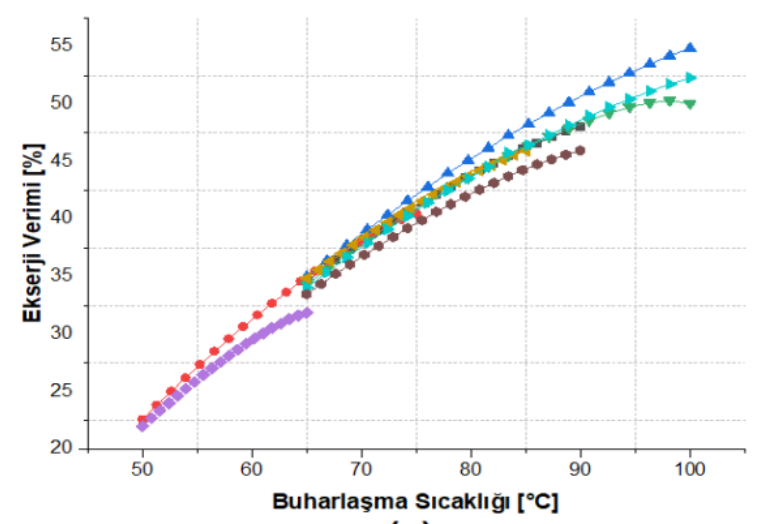

(e)

Şekil 4. Kuru ve ıslak akışkanların termodinamik performanslarının karşılaştırılması a) Pompa Işsi, b) Türbin Işsi, c) Giren Isl, d) Isıl Verim, e) Ekserji Verimi

Islak akışkanların kaynama noktası sıcaklıklarının diğer tür akışkanlara göre çok düşük olduğu görülmektedir. En düşük kaynama noktası sıcaklığının $-51.7{ }^{\circ} \mathrm{C}$ ile R32'de olduğu belirtilmiştir. Kritik sıcaklıklarda ise R125 ve R32'nin düşük değere sahip olduğu, diğer akışkanların ise birbirine yakın olduğu görülmektedir. Tüm akışkanların $30^{\circ} \mathrm{C}$ 'ye karşılık gelen yoğuşma basınçları ile $100{ }^{\circ} \mathrm{C}$ ' deki buharlaşma basınçları incelendiğinde diğer tür akışkanlara kıyasla ıslak akışkanların yüksek basınç değerlerine sahip olduğu dikkat çekmektedir. Islak akışkanlar içerisinden ise en düşük kritik basınç değerine R152a 4.52 MPa ve R134a 4.06 MPa olarak görülmüştür. 


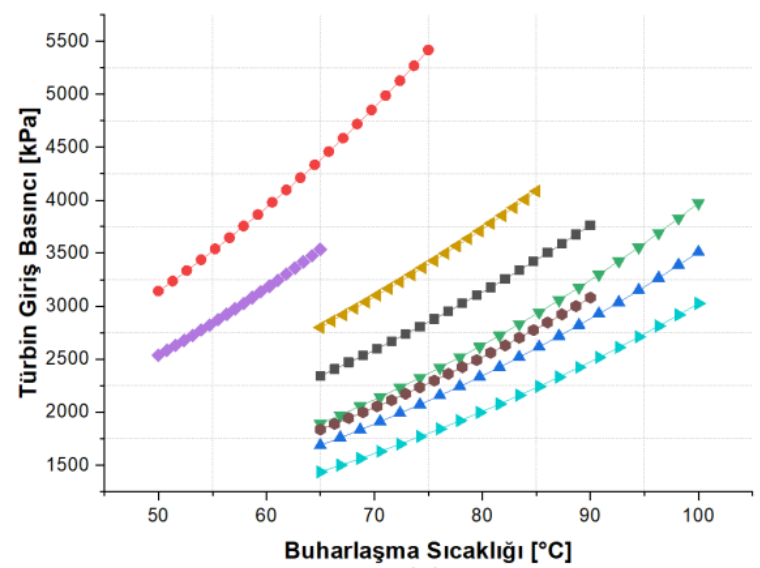

(a)

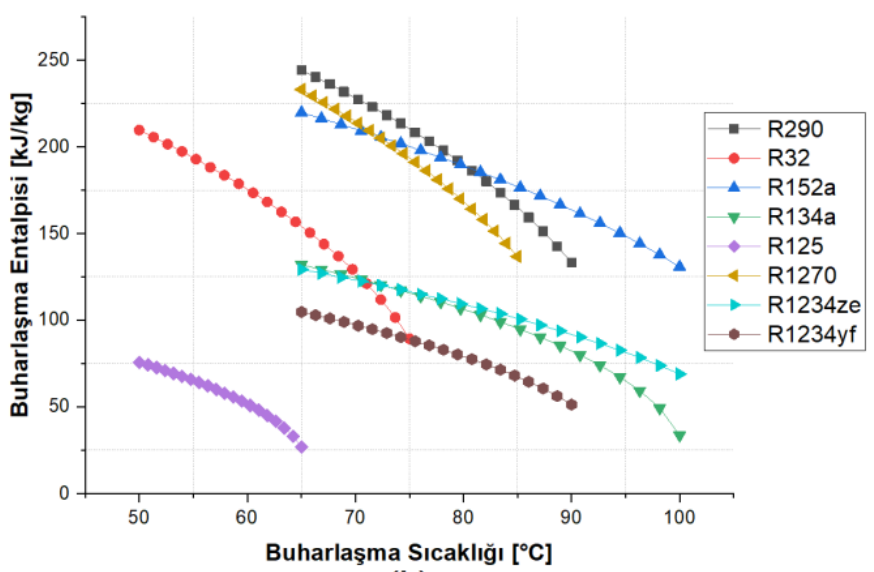

(b)

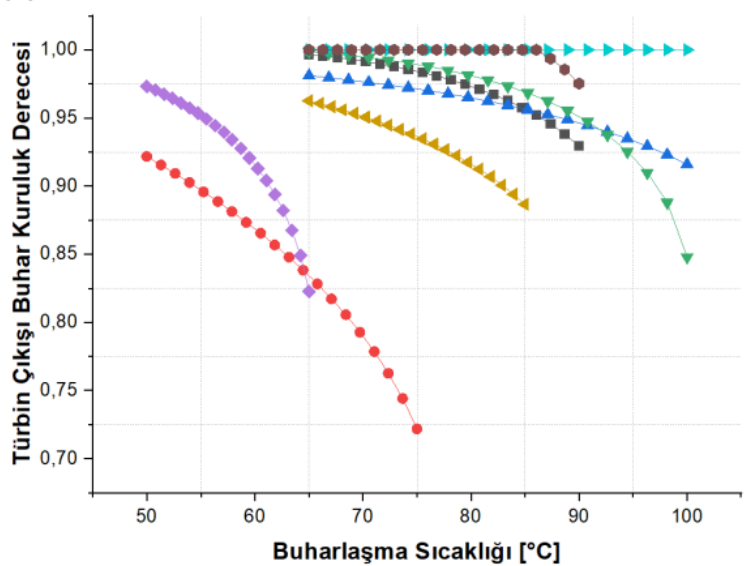

(c)

Şekil 5. Kuru ve ıslak akışkanların termodinamik performanslarının karşılaştırılması a) Türbin giriş basıncı, b) Buharlaşma Entalpisi $\left(h_{f g}\right)$, c) Türbin çıkışı buharın kuruluk derecesi

R123'lü sistemde oluşan basınç fark1 R152a'lı sistemde oluşan basınç farkından \%75 daha azdır, ayrıca özgül hacmi de \%38 daha az olarak tespit edilmiştir. Hem basınç farkının hem de özgül hacminin düşük olmasından dolayı R123'lü sistemin pompa işi R152a'lı sistemden \%85 daha az bulunmuştur. R1234ze'li sistemde de yüksek basınç farkı görülmesine rağmen yine de R152a'lı sistemden \%13 daha az bir basınç farkına sahiptir. Ayrıca özgül hacmi de \%22 daha azdır. Bundan dolayı R1234ze'li sistemde R152a'lı sistemden \%32 daha düşük pompa işi tespit edilmiştir.

Bu çalışmada Organik Rankine Çevrimi'nde akışkan seçiminin sistem performasındaki önemi belirtilmiş olup; farklı türden akışkanların çevresel ve termodinamik özellikleri belirlenen performans parametreleri ile karşılaştırılmışlardır.

\section{KAYNAKÇA (REFERENCES)}

[1] H. Wang, H. Li, L. Wang, X. Bu, Thermodynamic Analysis of Organic Rankine Cycle with Hydrofluoroethers as Working Fluids, Energy Procedia. 105 (2017) 1889-1894. doi:10.1016/j.egypro.2017.03.554.

[2] A. Uusitalo, J. Honkatukia, T. Turunen-Saaresti, A. Grönman, Thermodynamic evaluation on the effect of working fluid type and fluids critical properties on design and performance of Organic Rankine Cycles, Journal of Cleaner Production. 188 (2018) 253-263. doi:10.1016/j.jclepro.2018.03.228.

[3] A. Ergün, Organik Rankine Çevrimi Prensibine Göre Çalışan Bir Jeotermal Elektrik Santralinin 
Termoekonomik Analizi, Doktora Tezi, Fen Bilimleri Enstitüsü, Karabük Üniversitesi, Karabük, Türkiye, 2014.

[4] M. Eyidoğan, Organik Rankine Çevrimli Güç Üretim Sisteminin Enerji ve Ekserji Analizi, Doktora Tezi, Karabük Üniversitesi, Karabük, Türkiye, 2014.

[5] A. Giuffrida, A theoretical study on the performance of a scroll expander in an organic Rankine cycle with hydrofluoroolefins (HFOs) in place of R245fa, Energy. 161 (2018) 1172-1180. doi:10.1016/j.energy.2018.07.146.

[6] J. Yang, Z. Sun, B. Yu, J. Chen, Experimental comparison and optimization guidance of R1233zd(E) as a drop-in replacement to R245fa for organic Rankine cycle application, Applied Thermal Engineering. 141 (2018) 10-19. doi:10.1016/j.applthermaleng.2018.05.105.

[7] A. Behzadi, E. Gholamian, E. Houshfar, A. Habibollahzade, Multi-objective optimization and exergoeconomic analysis of waste heat recovery from Tehran's waste-to-energy plant integrated with an ORC unit, Energy. 160 (2018) 1055-1068. doi:10.1016/j.energy.2018.07.074.

[8] A.H. Bademlioglu, R. Yamankaradeniz, O. Kaynakli, Exergy analysis of the organic rankine cycle based on the pinch point temperature difference, Journal of Thermal Engineering. 5 (2019) 157-165. doi:10.18186/THERMAL.540149.

[9] R. Şahin, S. Ata, A. Kahraman, Organik Rankine Çevriminde Farklı Tip Akışkanlarda Türbin Giriş Sıcaklığı ve Basıncının Sistem Bileşenlerindeki Tersinmezlik Değerlerine Etkisinin Belirlenmesi Determination of Impact of Turbine Input Temperature and Pressure on the Irreversibility Values, Çukurova Üniversitesi Mühendislik-Mimarlık Fakültesi Dergisi. 33 (2018) 225-236.

[10] H. Xi, M.J. Li, C. Xu, Y.L. He, Parametric optimization of regenerative organic Rankine cycle (ORC) for low grade waste heat recovery using genetic algorithm, Energy. 58 (2013) 473-482. doi:10.1016/j.energy.2013.06.039.

[11] K. Rahbar, S. Mahmoud, R.K. Al-Dadah, N. Moazami, Parametric analysis and optimization of a smallscale radial turbine for Organic Rankine Cycle, Energy. 83 (2015) 696-711. doi:10.1016/j.energy.2015.02.079.

[12] J. Sarkar, Generalized pinch point design method of subcritical-supercritical organic Rankine cycle for maximum heat recovery, Energy. 143 (2018) 141-150. doi:10.1016/j.energy.2017.10.057.

[13] J. Li, Q. Liu, Z. Ge, Y. Duan, Z. Yang, Thermodynamic performance analyses and optimization of subcritical and transcritical organic Rankine cycles using R1234ze(E) for $100-200{ }^{\circ} \mathrm{C}$ heat sources, Energy Conversion and Management. 149 (2017) 140-154. doi:10.1016/j.enconman.2017.06.060.

[14] Q. Zhu, Z. Sun, J. Zhou, Performance analysis of organic rankine cycles using different working fluids, Thermal Science. 19 (2015) 179-191. doi:10.2298/TSCI120318014Z.

[15] F. Vélez, J.J. Segovia, M.C. Martín, G. Antolín, F. Chejne, A. Quijano, Comparative study of working fluids for a Rankine cycle operating at low temperature, Fuel Processing Technology. 103 (2012) $71-$ 77. doi:10.1016/j.fuproc.2011.09.017.

[16] A. Javanshir, N. Sarunac, Thermodynamic analysis of a simple Organic Rankine Cycle, Energy. 118 (2017) 85-96. doi:10.1016/j.energy.2016.12.019.

[17] J. Bao, L. Zhao, A review of working fluid and expander selections for organic Rankine cycle, Renewable and Sustainable Energy Reviews. 24 (2013) 325-342. doi:10.1016/j.rser.2013.03.040.

[18] J.M. Calm, G.C. Hourahan, Refrigerant data update, HPAC Heating, Piping, AirConditioning Engineering. 79 (2007) 50-64. 